\title{
SURGICAL OUTCOME OF UNILATERAL LATERAL RECTUS RECESSION AND MEDIAL RECTUS RESECTION IN LARGE-ANGLE EXOTROPIA
}

\author{
Sunil Kumar1, Vanlal Muanpuii Ralte ${ }^{2}$ \\ ${ }^{1}$ Associate Professor, Department of Ophthalmology, Regional Institute of Ophthalmology, RIMS, Ranchi, Jharkhand. \\ 2Junior Resident, Department of Ophthalmology, Regional Institute of Ophthalmology, RIMS, Ranchi, Jharkhand.
}

\begin{tabular}{l} 
ABSTRACT \\
\hline BACKGROUND \\
Exotropia is a manifest outward deviation of the visual axes, which is either constantly or intermittently present. Untreated poorly \\
controlled intermittent exotropia later progresses to constant exotropia. Sensory exotropia is unilateral divergent misalignment of \\
the eyes, resulting from loss of vision or long-standing poor vision in an eye. \\
The objective of this study is to evaluate the result of unilateral lateral rectus recession and medial rectus resection in large- \\
angle exotropia more than 60 PD and to assess intraoperative and postoperative complications. \\
Settings- Tertiary Eye Care Centre, Ranchi, India.
\end{tabular}

\section{MATERIALS AND METHODS}

Consecutive patients with large-angle exotropia more than 60 PD who underwent unilateral lateral rectus recession and medial rectus resection between January 2015 and December 2016 were retrospectively studied. Postoperative residual deviations and any intraoperative and postoperative complications were assessed.

\section{RESULTS}

The case series included sixteen patients ( 11 males and 5 females). Mean age of the patients were $21.25 \pm 4.31$ years. The mean preoperative deviations at distance and near were $67 \pm 12$ PD and $69 \pm 14$ PD respectively. The postoperative result showed that 11 patients had orthotropia (68.8\%), 3 patients (18.7\%) had undercorrection of 10 PD and two patients (12.5\%) had undercorrection of 15 - 20 PD. Only one patient with undercorrection of 20 PD required second surgery. None of the patients had any intraoperative complications related to surgery or anaesthesia.

\section{CONCLUSION}

Unilateral single stage two-muscle surgery gives good result and can be done as first procedure for large-angle exotropia of $>60$ PD.

\section{KEYWORDS}

Exotropia, Surgery, Lateral Rectus, Medial Rectus.

HOW TO CITE THIS ARTICLE: Kumar S, Ralte VM. Surgical outcome of unilateral lateral rectus recession and medial rectus resection in large-angle exotropia. J. Evolution Med. Dent. Sci. 2017;6(86):5937-5940, DOI: 10.14260/jemds/2017/1292

\section{BACKGROUND}

Exotropia is a manifest outward deviation of the visual axes, which is either constantly or intermittently present. Untreated poorly controlled intermittent exotropia later progresses to constant exotropia.

Sensory exotropia is unilateral divergent misalignment of the eyes, resulting from loss of vision or long-standing poor vision in an eye. The angles are characteristically large, ranging from 30 to 100 prism dioptres (PD) and increases gradually over time as long as the cause of visual deficit remains active. Treatment is directed to re-establish the normal ocular alignment and binocular vision. ${ }^{1}$ The preferred treatment for manifest exotropia is surgery. ${ }^{2}$ Large angle constant exotropia negatively impacts the way the patients see themselves and are perceived by others. The benefits of

'Financial or Other Competing Interest': None.

Submission 05-09-2017, Peer Review 13-10-2017,

Acceptance 19-10-2017, Published 26-10-2017.

Corresponding Author:

Dr. Sunil Kumar,

Associate Professor,

Department of Ophthalmology,

Regional Institute of Ophthalmology,

RIMS, Ranchi, Jharkhand.

E-mail: drsunilpgi12@yahoo.com

DOI: $10.14260 /$ jemds $/ 2017 / 1292$

(c) (i) $(3)$ surgical treatment of exotropia in adults is well proven, both psychologically and visually. The surgical treatment for largeangle exotropia has been a subject of sufficient debate. A variety of surgical plans have been described including two, three or four horizontal rectus muscles recession and resections with or without adjustable suture technique. ${ }^{3}$ In more recent studies, the management of large-angle exotropia falls into two surgical approaches.

1. Large bilateral lateral rectus recession is done when the acuity is good in each eye.

2. If one eye is amblyopic, a maximal or supramaximal unilateral recess- resect procedure is performed.

Records of previous studies have shown that monocular surgery had shown good results for exotropia of $<60$ PD. But for exotropia of $>60 \mathrm{PD}$, monocular surgery was not so effective. 4

Therefore, this study was done to evaluate the outcome of single-stage unilateral two muscle surgery for large-angle exotropia (> 60 PD).

\section{MATERIALS AND METHODS}

The case series included sixteen consecutive patients with large-angle exotropia of more than $60 \mathrm{PD}$, who underwent unilateral two muscle surgery from January 2015 - December 2016 at Regional Institute of Ophthalmology, Rajendra 
Institute of Medical Sciences, Ranchi, India were retrospectively analysed. Approval was taken from the Institute Ethics Committee for the study.

The exclusion criteria included:

1. Deviation $<60$ PD and $>80$ PD.

2. Paralytic squint.

3. Any history of previous squint surgery.

4. Followup of $<6$ months.

In all the patients, a detailed history was taken regarding age of onset of squint, family history, whether intermittent or constant, history of diplopia, ocular trauma or any previous surgery.

All patients underwent complete ocular examination before surgery. Visual acuity was measured using Snellen chart, E chart or broken ring chart with and without glasses.

The ocular alignment was assessed with the help of cover/ uncover test. Amount of deviation were measured by alternate prism bar cover test, both for distance and near.

Slit lamp examination was done for every patient to rule out any anterior segment pathology. Intraocular pressures were measured using Goldmann Applanation tonometry. Posterior segment was also evaluated by direct ophthalmoscopy and slit lamp biomicroscopy using $90 \mathrm{D}$ lens to rule out any pathology.

Patients with exotropia of 60 - 80 PD underwent lateral rectus recession of $8-10 \mathrm{~mm}$ and medial rectus resection of 7 - $9 \mathrm{~mm}$ under peribulbar anaesthesia. All the surgeries were performed by a single surgeon (SK), based on the angle of exotropia measured preoperatively.

The postoperative followup were done at day 1 , 1 week, 1 month, 3 months and 6 months. In all the follow-ups, ocular alignment were assessed with the help of cover/ uncover test. Any amount of overcorrection or undercorrection were measured by alternate prism bar cover test.

\section{Statistical Analysis}

The data were analysed by SPSS software for Windows (version 18.0, SPSS Inc., Chicago, IL, USA). The quantitative data including age at surgery and pre-operative amount of deviations in prism dioptres at distance and near and amount of surgery in millimetre of lateral rectus recession and medial rectus resection were represented in Mean \pm SD. Surgical success were defined as postoperative deviation within $10 \mathrm{PD}$ and represented as percentage.

\section{RESULT}

The case series included 16 patients with exotropia ranging from 60 - 80 PD, who underwent unilateral single stage twomuscle surgery. Eleven patients $(68.7 \%)$ were males and five patients $(31.3 \%)$ were females. Mean age of the patients were $21.25 \pm 4.31$ years (range $12-28$ years). The mean preoperative deviations at distance and near were $67 \pm 12 \mathrm{PD}$ and $69 \pm 14$ PD respectively. None of the patients had limitation of ocular movement and any lateral incomitance.

In all patients, unilateral recession of lateral rectus and resection of medial rectus were done in single stage. Mean recession of lateral rectus done were $9.1 \pm 1.2 \mathrm{~mm} \mathrm{(8-10}$ $\mathrm{mm}$ ) and mean resection of medial rectus were $7.9 \pm 0.8 \mathrm{~mm}$ (7 - $9 \mathrm{~mm}$ ). None of the patients had any intraoperative complications related to surgery or anaesthesia. The mean followup period was $8.2 \pm 3.7$ months ( 6 - 19 months).

The postoperative result showed that 11 patients $(68.8 \%)$ had orthotropia [Figure 1], three patients (18.7\%) had undercorrection of $10 \mathrm{PD}$ [Figure 2] and two patients (12.5\%) had undercorrection of 15 - 20 PD [Figure 3]. Thus, fourteen patients $(87.5 \%)$ in our study had good cosmetically acceptable outcome. Only one patient with undercorrection of $20 \mathrm{PD}$ required second surgery.

None of the patients in our study had any significant limitation of ocular movement after surgery. Also, none of the patients complained of diplopia postoperatively.

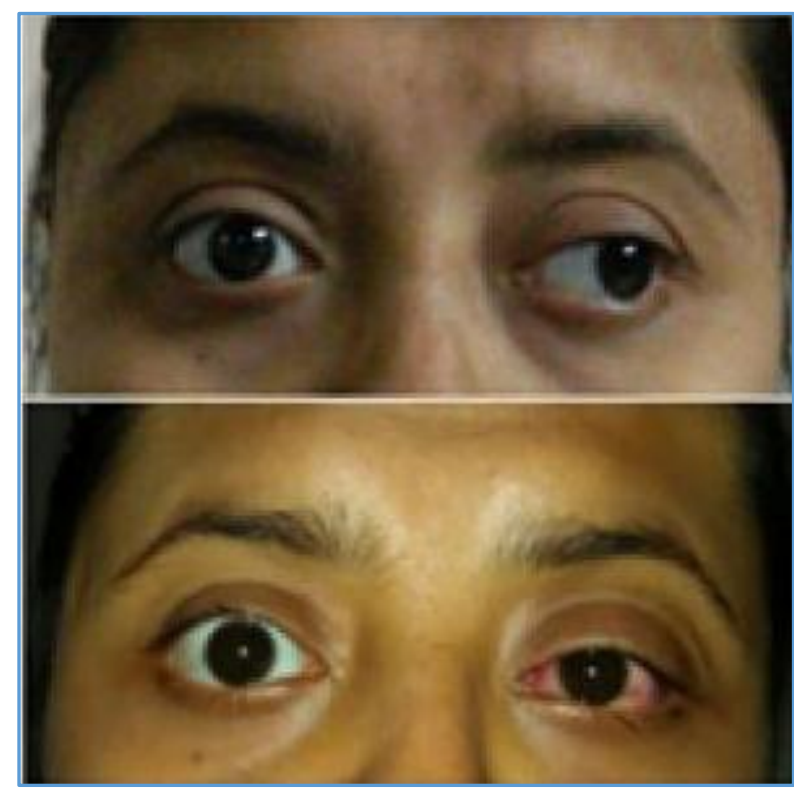

Figure 1
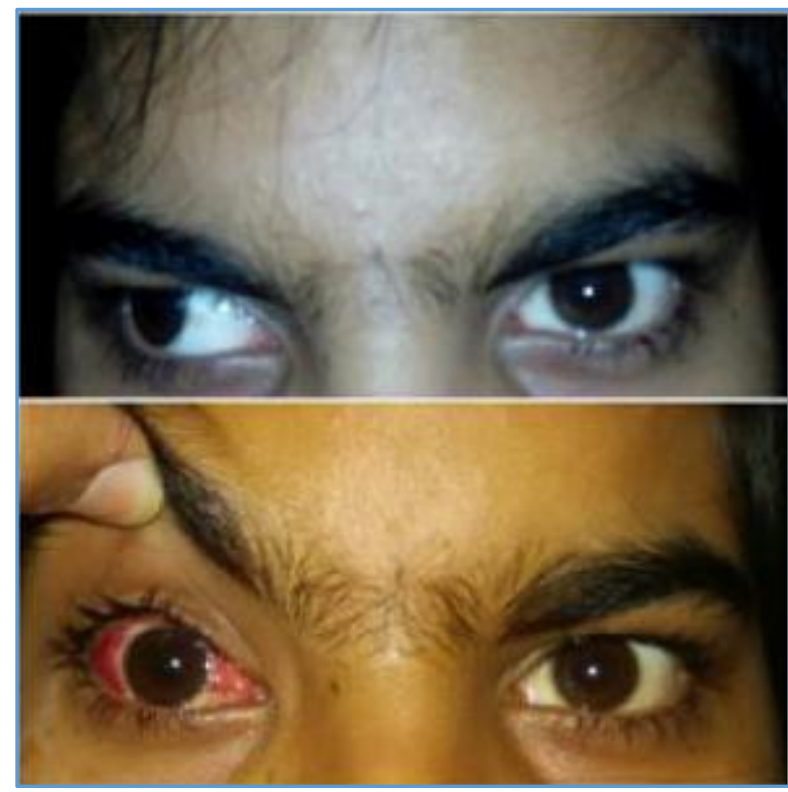

Figure 2 


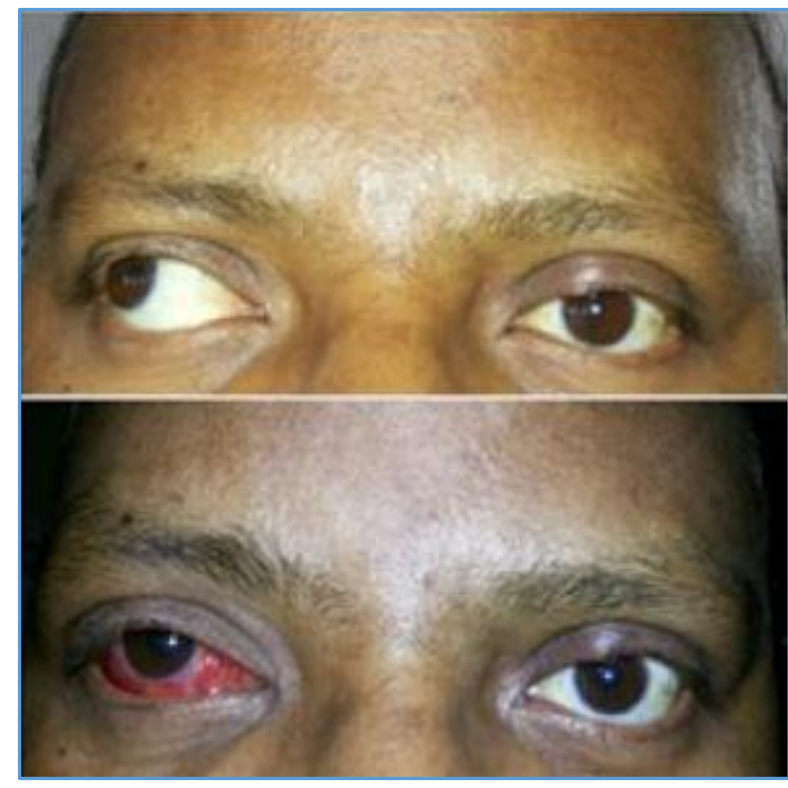

Figure 3

\section{DISCUSSION}

There have been various studies regarding the management of large-angle exotropia, both surgical and non-surgical. The surgical technique includes two-, three- or four-muscle surgery done in one or two stages. ${ }^{5-8}$ It is advised by most authors that up to two-muscle surgery should be performed in one stage and if there is any exodeviation remaining, it should be corrected by a second stage surgery. ${ }^{6}$ According to Kushner et al, unilateral recession and resection procedure should be performed for primary exotropia. ${ }^{9}$

In our study, we have reviewed patients with exotropia of $>60$ PD who underwent single stage two muscle procedure. The added benefit of this procedure is that if in case a second operation is needed some muscles have been preserved for it. 10 The postoperative result in our study showed that $68.8 \%$ patients had orthotropia, $18.7 \%$ patients had undercorrection of $10 \mathrm{PD}$ and $12.5 \%$ patients had undercorrection of 15 - 20 PD. Thus, $87.5 \%$ patients in our study had good cosmetically acceptable outcome.

The success rate of our study is similar to various previous studies done by other authors. A report given by Ganguly et al ${ }^{11}$ showed a success rate of $83.3 \%$ with unilateral two muscle surgery in exodeviation of 40 - 80 PD. In a study by Schwartz et al, ${ }^{12}$ two muscle surgery had good result for large-angle exotropia and $77 \%$ of their cases achieved a postoperative alignment of \pm 15 PD. For mediumangle exotropia two muscle surgery may be an option, while large-angle exotropia may need three or four muscle surgery. 10

According to Gezer and Kushner, they identified that the most important factor to determine the successful outcome of the surgery in exotropia is the preoperative deviation. ${ }^{13,14}$ Thus, it has been accepted by many authors that preoperative deviation plays the most important role in determining the postoperative alignment. But there is no definite cut-off to bring about a favourable outcome with two muscles procedure, because other factors play a role as well such as surgical technique and dose. ${ }^{10}$

The mean age in our study is $21.25 \pm 4.31$ (12 - 28 years). This higher age group could be due to patient's ignorance and late presentation to tertiary care centre. A study by Koo et al shows that the postoperative result does not depend on the age of operation. The favourable age for operation is when the child can be assessed for orthoptic correction and also when the functional and cosmetic symptoms become too apparent. ${ }^{15-18}$

According to the study conducted by Junejo SA et al, ${ }^{19}$ the desired postop effect was seen with preoperative deviation of $<60$ PD. With deviation > 60 PD, there was difficulty in aligning the eyes with operation only on one eye. For these cases, a second surgery was required with more than two muscle procedure. ${ }^{19}$ In our study, one patient with exotropia $>60$ PD required second surgery.

Although, it has been recommended by most authors not to exceed $7 \mathrm{~mm}$ medial rectus resection and $8 \mathrm{~mm}$ lateral rectus recession in order to avoid ocular movement limitations, $4,20,21$ in our study we have done lateral rectus recession of $8-10 \mathrm{~mm}$ and medial rectus resection of $7-9$ $\mathrm{mm}$. None of the patients in our study had significant postoperative restriction of ocular motility. Also, none of the patients complained of diplopia postoperatively.

\section{CONCLUSION}

Our study showed that single stage two muscle surgery gives good result for large-angle exotropia > 60 PD. Also, large amount of lateral rectus recession and medial resection was safe and does not produce any significant postoperative motor deficit and diplopia. So single stage two muscle surgery should be done as first procedure for large-angle exotropia of $>60$ PD.

\section{REFERENCES}

[1] Eibschitz-Tsimhoni M, Archer SM, Furr BA, et al. Current concepts in the management of concomitant exodeviations. Compr Ophthalmol Update 2007;8(4):213-23.

[2] Asjes-Tydeman WL, Groenewoud H, Van der Wilt GJ. Timing of surgery for primary exotropia in children. Strabismus 2006;14(4):191-7.

[3] Yang M, Chen J, Shen T, et al. Single stage surgical outcomes for large angle intermittent exotropia. PLoS One 2016;11(2):e0150508.

[4] Millan T, de Carvalho KM, Minguini N. Results of monocular surgery under peribulbar anaesthesia for large-angle horizontal strabismus. Clinics (Sao Paulo) 2009;64(4):303-8.

[5] Lau FHS, Fan DSP, Yip WWK, et al. Surgical outcome of single-staged three horizontal muscles squint surgery for extra-large angle exotropia. Eye (Lond) 2010;24(7):1171-6.

[6] Mulberger RD, McDonald PR. Surgical management of nonparalytic exotropia. AMA Arch Ophthalmol 1954;52(5):664-8.

[7] Aslanis D, Follidi V, Constantopoulos I, et al. Surgical results in childhood primary comitant large-angle exotropia. J Fr Ophthalmol 2006;29(1):37-42.

[8] Thomas S, Guha S. Large-angle strabismus: can a single surgical procedure achieve a successful outcome? Strabismus 2010;18(4):129-36.

[9] Kushner BJ, Fisher MR, Lucchese NJ, et al. Factors influencing response to strabismus surgery. Arch Ophthalmol 1993;111(1):75-9. 
[10] Saleem QA, Cheema AM, Tahir MA, et al. Outcome of unilateral lateral rectus recession and medial rectus resection in primary exotropia. BMC Res Notes 2013;6:257.

[11] Ganguly S, Pradhan R. Effect of monocular surgery for large-angle horizontal deviation in adults. Nepal J Ophthalmol 2011;3(1):27-30.

[12] Schwartz RL, Calhoun JH. Surgery of large angle exotropia. J Pediatr Ophthalmol Strabismus 1980;17(6):359-63.

[13] Gezer A, Sezen F, Nasri N, et al. Factors influencing the outcome of strabismus surgery in patients with exotropia. J AAPOS 2004;8(1):56-60.

[14] Kushner BJ. Selective surgery for intermittent exotropia based on distance/near differences. Arch Ophthalmol 1998;116(3):324-8.

[15] Koo NK, Lee YC, Lee SY. Clinical study for the undercorrection factor in intermittent exotropia. Korean J Ophthalmol 2006;20(3):182-7.
[16] Richard JM, Parks MM. Intermittent exotropia. Surgical results in different age groups. Ophthalmology 1983;90(10):1172-7.

[17] Keenan JM, Willshaw HE. The outcome of strabismus surgery in childhood exotropia. Eye 1994;8(Pt 6):6327.

[18] Stoller SH, Simon JW, Lininger LL. Bilateral lateral rectus recession for exotropia: a survival analysis. J Pediatr Ophthalmol Strabismus 1994;31(2):89-92.

[19] Junejo SA, Ansari MA. Outcome of monocular surgery for horizontal strabismus in Hyderabad. Clin Ophthalmol 2010;4:269-73.

[20] Damanakis AG, Arvanitis PG, Ladas ID, et al. $8 \mathrm{~mm}$ bimedial rectus recession in infantile esotropia of 80 90 prism dioptres. Br J Ophthalmol 1994;78(11):8424.

[21] Prieto-Díaz J, Souza-Dias C. Esotropias. In: Prieto-Díaz, Souza-Dias C. eds. Estrabismo. São Paulo: Livraria Santos Editora 2002:149-99. 